\title{
Selective Flocculation of Banded Hematite Quartzite (BHQ) Ores
}

\author{
L. Panda, B. Das, D.S. Rao and B.K. Mishra*
}

Institute of Minerals and Materials Technology, Council of Scientific and Industrial Research, (CSIR), Bhubaneswar751013, India

\begin{abstract}
The recovery of fine hematite particles from banded hematite quartzite (BHQ) ore with potato starch has been investigated using selective flocculation. Microscopic features, coupled with x-ray diffraction (XRD), and Fourier transforms infrared (FTIR) spectroscopic data provide evidences for adsorption of starch molecules on hematite surface. The starch molecules show good selectivity for hematite particles in the $\mathrm{pH}$ range of 8.5-9.5 and in the reagent concentration range of 20-40 mg/l. The Scanning electron microscope (SEM) studies show that flocs of hematite particles are larger and appear to be denser than that of quartz. Initial results with 1:1 hematite-quartz mixture indicated that it is possible to achieve an iron concentrate of $64.5 \%$ Fe with $92.0 \%$ of iron recovery from a feed of $34 \%$ Fe. However under optical conditions of $\mathrm{pH}$ and reagent concentration, the BHQ ore could be upgraded from an initial grade of $38.9 \% \mathrm{Fe}$ to $57.2 \%$ Fe with $71 \%$ recovery. The overall results indicate that separation of very fine grained hematite present in the BHQ iron ore is feasible by selective flocculation.
\end{abstract}

Keywords: BHQ ore, Selective flocculation, Potato starch, XRD, FTIR, SEM.

\section{INTRODUCTION}

Selective flocculation is a useful technique commonly used to enrich ultra fine mineral particles that respond poorly to conventional beneficiation techniques. The beneficiation techniques, such as gravity separation, magnetic separation, or flotation, are generally ineffective in treating the ultra-fine particles. Hence in practice these particles are usually discarded as tailings prior to concentration. For example, in India, 10-12 million tons of iron ore slimes are being generated every year during the concentration of hematite ore and discarded without any further utility. In order to recover values from ultra-fines, several industries are employing selective flocculation technique to treat fines and slimes generated during mining and processing of the ore.

Similarly, the process to recover iron values from the banded iron ore formation (BIF) - banded hematite quartzite (BHQ), banded hematite jasper (BHJ) and banded magnetite quartzite (BMQ) - are yet to be explored due to the fine nature of the ore which is difficult to treat by straight-forward selective flocculation means. These low grade BIF ores contain $28-40 \% \mathrm{Fe}$ and $40-55 \% \mathrm{SiO}_{2}$. The minerals are liberated at extremely fine sizes and in addition, these ores typically consist of bands of iron-bearing hematite or magnetite intergrowth with quartz and for this reason, upon breakage, the nature of particle surface appears quite complex. These aspects of particle characteristic tend to have a strong bearing on any technique that relies on surface properties to induce separation. It is therefore imperative to develop a recipe to adopt selective flocculation technique to treat low grade ores and waste slimes of banded nature. The possible

*Address correspondence to this author at the Institute of Minerals and Materials Technology, Council of Scientific and Industrial Research, (CSIR), Bhubaneswar-751013, India; Tel: 91-674-2581126;

Fax: 91-674-2581160; E-mail: bkm@immt.res.in beneficiation techniques that have been tried to recover iron values from these banded ores is by grinding to liberation size followed by high intensity magnetic separation and flotation [1]. However, adaptation of selective flocculation technique has been a challenge.

A number of successful selective flocculation studies have been achieved at laboratory as well as pilot-plant scale using various mineral/ore slimes such as bauxite, coal, phosphate, chromite, hematite, magnetite, etc., [2-12]. The success of such technique relies heavily on the chemistry of the process. A review of the literature shows that the use of various starch molecules from potato, corn, tapioca, cassava, etc., as flocculants have worked well for iron-bearing particles compared to other synthetic flocculants. For example, selective flocculation study of hematite and hematite-silica mixture clearly indicates the superior selectivity of starch in comparison to polyacrylic acid (PAA) and polyacrylamide $[13,14]$. Selective flocculation studies employing starch as the flocculant to treat naturally occurring iron ore slimes (hematite) of India have shown that a concentrate containing $65 \% \mathrm{Fe}, 1.8 \% \mathrm{Al}_{2} \mathrm{O}_{3}$ and $1.4 \% \mathrm{SiO}_{2}$ could be achieved from a plant tailing containing $52.5 \% \mathrm{Fe}, 7.4 \% \mathrm{Al}_{2} \mathrm{O}_{3}$ and $7.8 \%$ $\mathrm{SiO}_{2}$ [15]. Some fundamental studies on starch have indicated that native starch is a polysaccharide mainly consisting of two different types of glucose polymers: amylopectin and amylose. The amylopectine component of starch takes part in flocculation but the amyloses are unable to flocculate any mineral. Several scientific studies such as thermogravimetry, electrophoresis and FTIR spectroscopy have indicated that adsorption of starch onto hematite surface is due to the availability of higher concentration of hydroxylated metal adsorption sites and that the flocculation occurs by the classical bridging mechanism and formation of a surface complex $[16,17]$. 
Use of starch is quite common for flocculation purpose and several applications of starch can be found in areas like flotation, adhesives, drug deliveries, and selective flocculation [18-22]. Given the structure of the starch we believe it is an excellent surface modulator which is particularly suitable to act on the surface of BIF ore which in itself is structurally complex. In this paper, we report a proven application of causticised potato starch as a selective flocculant for ultrafine hematite particles present in banded hematite quartzite (BHQ).

\section{MATERIALS AND METHODS}

\section{Sample Preparation}

The BHQ ore, pure quartz, and pure hematite were collected from different mines of Odisha, India. The chemical compositions of mineral samples under study are shown in Table 1. The hematite sample contains $97.2 \% \quad \mathrm{Fe}_{2} \mathrm{O}_{3}$ with very low amount of impurities. The quartz sample is $99.4 \%$ pure. The BHQ sample contains 55.3\% $\mathrm{Fe}_{2} \mathrm{O}_{3}, 42.5 \% \mathrm{SiO}_{2}$, and $1.0 \% \mathrm{Al}_{2} \mathrm{O}_{3}$. It is observed that silica is the major impurity present in the BHQ sample. The percentages of other impurities are comparatively small. For flocculation study, the as received BHQ ore was crushed in a laboratory jaw crusher followed by roll crusher to reduce the particle size. The crushed ore was further reduced to $20 \mu \mathrm{m}$ size in a laboratory ball mill $(300 \times 300 \mathrm{~mm})$ with required weight of balls. The lumpy hematite or quartz samples were also crushed, hammered, and carefully ground in a ball mill and wet screened to below $20 \mu \mathrm{m}$. The ground quartz particles were further leached with dilute $\mathrm{HCl}$ to remove any contaminated iron particles in it. It was washed several times with distilled water and finally dried at $105^{\circ} \mathrm{C}$. A laser particle size analyzer named CILAS-1064 was used for the measurement of particle size. The results are presented in Fig. (1) for all the three different types of samples. These results indicate that the average particle size of BHQ, quartz, and hematite are 17.16, 17.56, and $3.22 \mu \mathrm{m}$ respectively.

Table 1. Chemical Analysis of BHQ, Hematite and Quartz Samples

\begin{tabular}{|c|c|c|c|}
\hline Constituents \% & BHQ & Hematite & Quartz \\
\hline \hline $\mathrm{Fe}(\mathrm{T})$ & 38.7 & 68.0 & Traces \\
\hline $\mathrm{Fe}_{2} \mathrm{O}_{3}$ & 55.3 & 97.2 & 0.005 \\
\hline $\mathrm{SiO}_{2}$ & 42.5 & 0.3 & 99.4 \\
\hline $\mathrm{Al}_{2} \mathrm{O}_{3}$ & 1.0 & 0.5 & 0.01 \\
\hline $\mathrm{CaO}$ & 0.02 & 0.02 & - \\
\hline $\mathrm{MgO}$ & 0.72 & 0.05 & - \\
\hline $\mathrm{MnO}$ & 0.032 & 0.08 & - \\
\hline $\mathrm{Na} 2 \mathrm{O}$ & 0.06 & Traces & - \\
\hline $\mathrm{LOI}$ & 0.54 & 0.5 & 0.1 \\
\hline
\end{tabular}

\section{Characterization Studies}

The microscopic study of the different size fractions of BHQ sample was carried out to identify the different minerals associated with the ore. The samples were examined by
FTIR spectra (Shimadzu FTIR, IR Prestige-21) using KBr as the reference to understand the interaction between iron and starch molecules. The structural characterization of the samples was carried out using a Philips X-ray diffractometer (PANalytical, X'pert) which was operated with $\mathrm{Cu}-\mathrm{K} \alpha$ radiation at $40 \mathrm{kV}$ and $30 \mathrm{~mA}$. SEM studies were carried out in a Hitachi $3400 \mathrm{~N}$ equipment to analyze the coagulation pattern between hematite particles in the presence of starch.

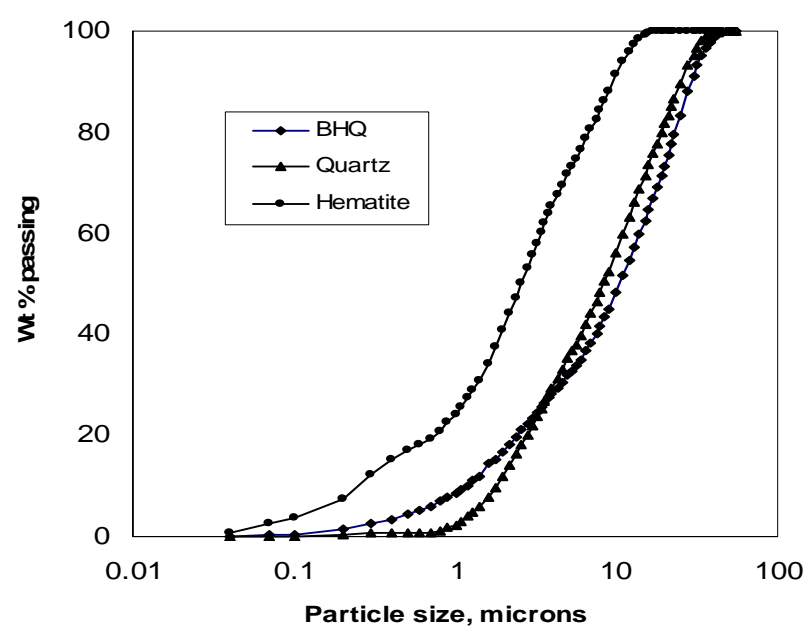

Fig. (1). Particle size analysis of BHQ, hematite and quartz samples.

\section{Flocculation Procedure}

The laboratory grade potato starch was used as the flocculant. A $1.0 \%$ starch solution was prepared by dissolving $1.0 \mathrm{gm}$ of starch and $0.5 \mathrm{gm}$ of sodium hydroxide to a volume of $100 \mathrm{ml}$ of water. The resultant solution was heated to $84^{\circ} \mathrm{C}$ and then rapidly cooled to room temperature using ice. The heating and cooling of the solution was carried out within five minutes. The flocculant was prepared daily before the start of the experiments. Flocculation experiments with BHQ, hematite, quartz and hematite-quartz mixtures were performed in a stirred beaker using the conventional jar and cylinder test. All the flocculation experiments were carried out at a pulp density of $5 \%$ solids by weight. The stirring speed was kept at $600 \mathrm{rpm}$. After adjusting the $\mathrm{pH}$, starch was added very slowly to the slurry under continuous mixing at low shear condition which was ensured by reducing the speed of the stirrer. The stirring was then continued for another two minutes and the resultant suspension was transferred to a measuring cylinder. The cylinder was inverted 3 times and the flocs formed were allowed to settle for one minute. The supernatant of the upper $80 \%$ part of the cylinder was siphoned off and the separated mass was washed with water. Finally, the floc and non-flocs were dried, weighed to determine the flocculated solids content and iron. In all the experiments, $\mathrm{NaOH}, \mathrm{HCl}$ or $\mathrm{Na}_{2} \mathrm{CO}_{3}$ of analytical grade was used as $\mathrm{pH}$ modifier. However, In some cases sodium hexameta-phosphate was used as the dispersant.

\section{RESULTS AND DISCUSSION}

Flocculation of particles relies on surface characteristics of the particles, nature of the aqueous environment, reagent type, etc. Microscopical studies indicated that BHQ sample 


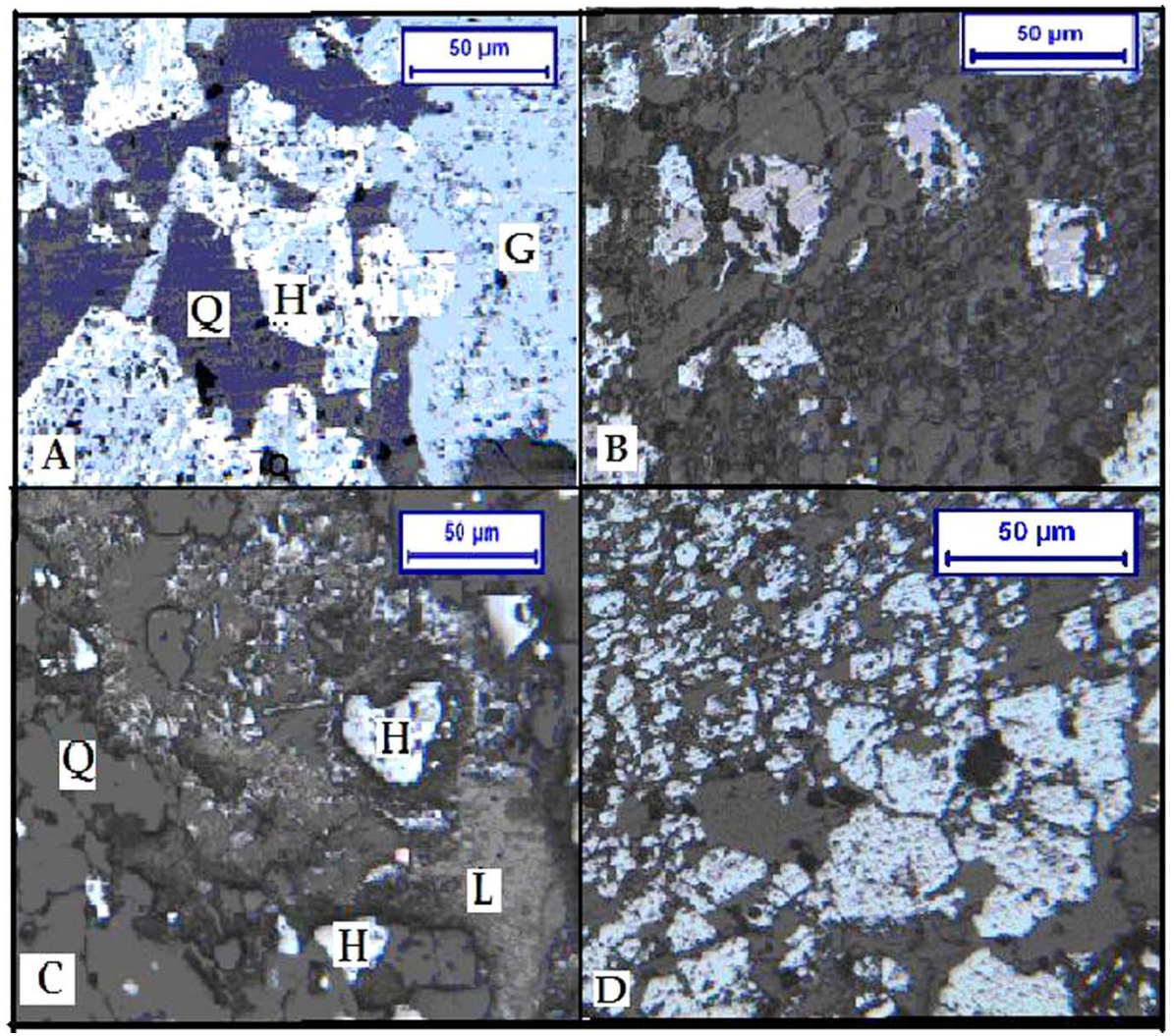

Fig. (2). A. Hematite $(H)$ encloses grains of goethite $(G)$ and quartz $(Q)$. B. Hematite (white) rimed round with magnetite and silicate grains. C. Few grains of hematite $(\mathrm{H})$ (flakes and needle type) are enclosed with limonitic D. Wide different size ranges of hematite (white) grains present along the inter-granular spaces of the silicates (quartz).

consists of hematite and quartz as the major minerals. Minor amounts of magnetite, goethite, limonite as well as kaolinite are also present in the sample. The microphotographs of BHQ sample are shown in Fig. (2). Widely varying hematite grains of different sizes are present along the inter-granular spaces of the silicates. As the particle sizes of hematite and silica are interlocked to each other, it is necessary to grind the material to a very fine size for effective liberation.

\section{Flocculation Studies}

\section{Effect of pH}

The effect of $\mathrm{pH}$ on amount of material settled in case of BHQ, hematite and quartz samples without addition of starch is shown in Fig. (3). It is observed that the amount settled decreased with increase in $\mathrm{pH}$, and a good dispersion is obtained in the alkaline $\mathrm{pH}$ region. All the three minerals showed good dispersion in the $\mathrm{pH}$ range of 9-11. The hematite particles appeared to have agglomerated in acidic $\mathrm{pH}$ region ( $\sim \mathrm{pH} 2.2)$ and correspondingly about $78 \%$ hematite particles were settled. It was also observed that the amount of settled mass of BHQ and quartz in comparison to hematite was very low. Hence due to difference in settling velocity of the minerals, selective flocculation for separation of hematite particles could be carried out below pH 9.0.

Fig. (4) shows the amount of material settled in the $\mathrm{pH}$ range of 2-12 for hematite, quartz, and BHQ with the addition of $20 \mathrm{mg} / \mathrm{l}$ of causticised starch. It is observed that the amount of BHQ and hematite that settled is about $98 \%$ where as, the same for quartz is only $60 \%$. From the results, it is clear that selective separation of iron from silica using starch as flocculants at slightly alkaline $\mathrm{pH}$ can be achieved.

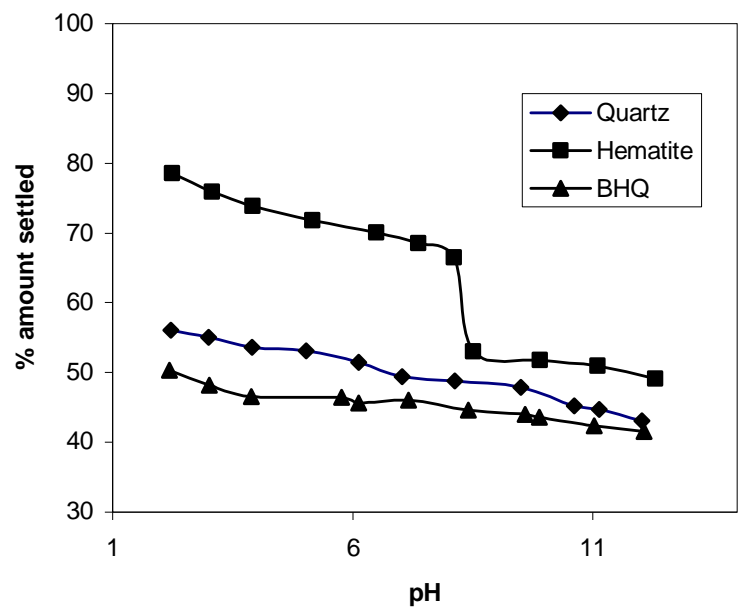

Fig. (3). Settling of minerals as a function of $\mathrm{pH}$.

\section{Effect of Starch Concentration}

Flocculation studies were conducted for BHQ, hematite, and quartz at $\mathrm{pH} 9.0$ as a function of starch addition. The effect of starch concentrations using $50 \mathrm{mg} / \mathrm{l}$ of sodium hexameta-phophate (Na-HMP) as dispersant is shown in Fig. (5). As seen from the figure, hematite and BHQ flocculate at a relatively low starch concentration. It is observed that 
about $95 \%$ of hematite is flocculated when starch dosage was just above $20 \mathrm{mg} / \mathrm{l}$. In contrast, amount of quartz that settled is comparatively less at the same dosage of starch. Hence the best separation of quartz from hematite is possible at $20 \mathrm{mg} / \mathrm{l}$ of starch concentration. Such behavior of the individual minerals is a prerequisite for a successful selective flocculation of BHQ.

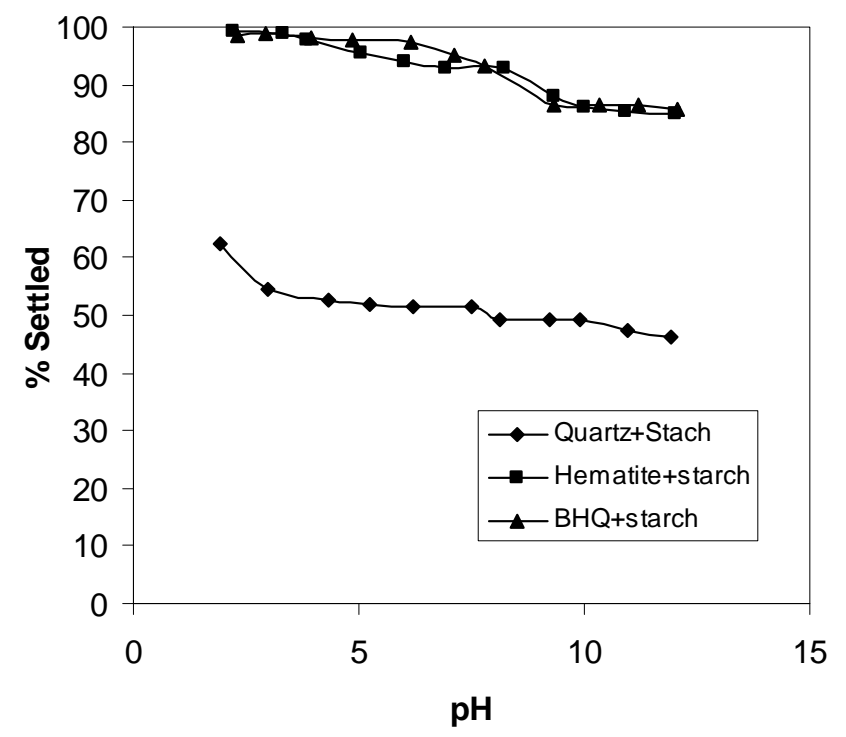

Fig. (4). Settling of minerals as a function of $\mathrm{pH}$ by the addition of $20 \mathrm{mg} / \mathrm{l}$ of causticised starch.

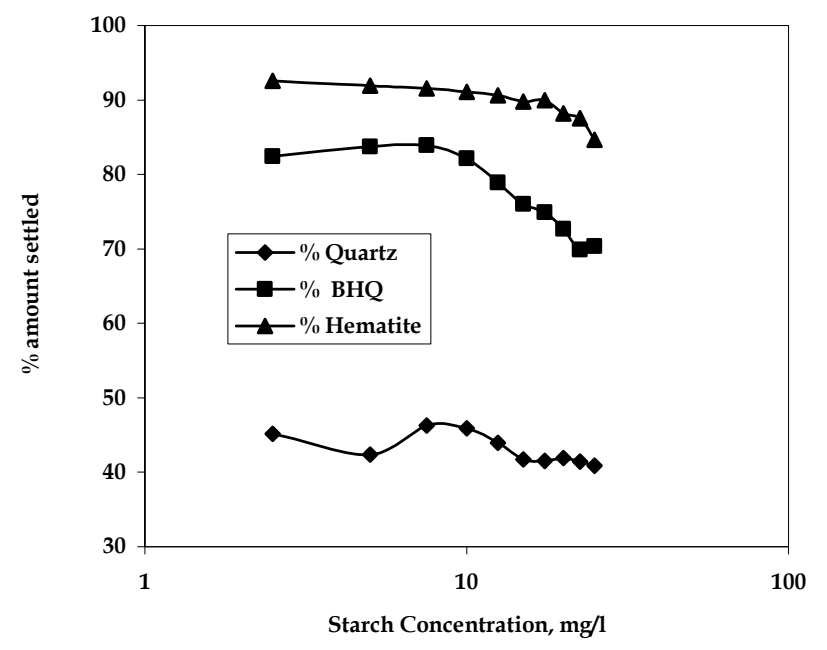

Fig. (5). Settling of minerals as a function of starch concentration, $10 \mathrm{mg} / \mathrm{l}, \mathrm{Na}-\mathrm{HMP}$ at $\mathrm{pH}$ 9.0.

\section{Effect of Dispersant}

The dispersion of any mineral prior to flocculation is important. Dispersants are used to prevent fine particles from aggregating and in many cases act to reduce the viscosity. During selective flocculation, it is essential to achieve the goal of separation so that the undesired minerals remain in dispersed state. The variation of the selective flocculation tendency of BHQ with various dispersants such as sodium silicate (Na-silicate), sodium hexameta-phosphate (NaHMP), sodium hydroxide $(\mathrm{NaOH})$ and sodium carbonate $\left(\mathrm{Na}_{2} \mathrm{CO}_{3}\right)$ is shown in Fig. (6). Out of the four reagents studied, it is seen that Na-HMP is a better dispersant since the amount settled is less in comparison to other reagents. Hence further experiments were carried out by adding a small dosage of Na-HMP for the separation of iron particles from quartz.

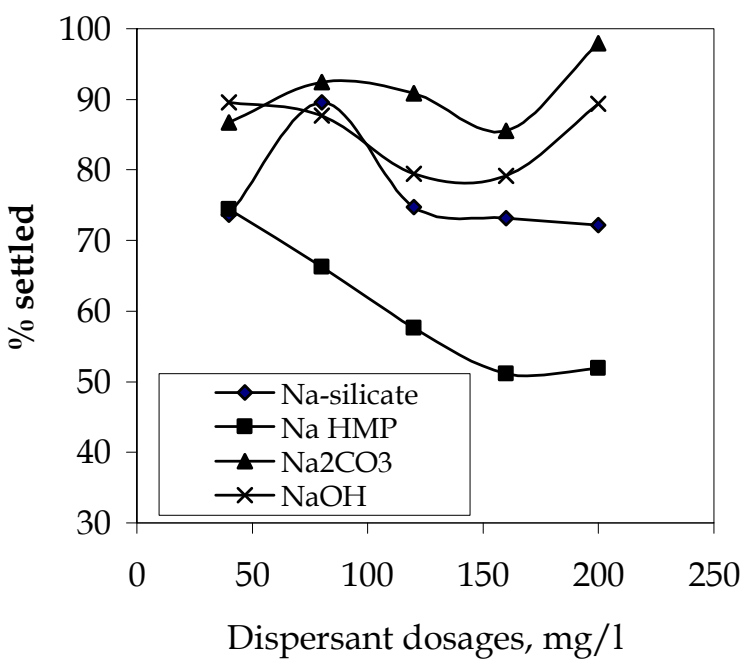

Fig. (6). Amount of BHQ particles settled as a function of dispersant concentration at $\mathrm{pH} 9.0$.

Based on the above studies, selective flocculation tests were conducted for 1:1 hematite-quartz mixture at $\mathrm{pH} 9.0$ as a function of starch addition. The results of the 1:1 hematitequartz mixture by the addition of $150 \mathrm{mg} / \mathrm{l}$ of Na-HMP are shown in Fig. (7). It is thus possible to achieve $64.5 \% \mathrm{Fe}$ with $92.0 \%$ of iron recovery from the resultant feed iron concentration of $34 \% \mathrm{Fe}$. The behavior of the mineral mixture thus indicates that flocculation of BHQ ore which essentially contains quartz and hematite would be possible. Accordingly, flocculation studies of BHQ ore under similar conditions were undertaken and the results are shown in Fig. (8). The results of this study indicate that it is possible to

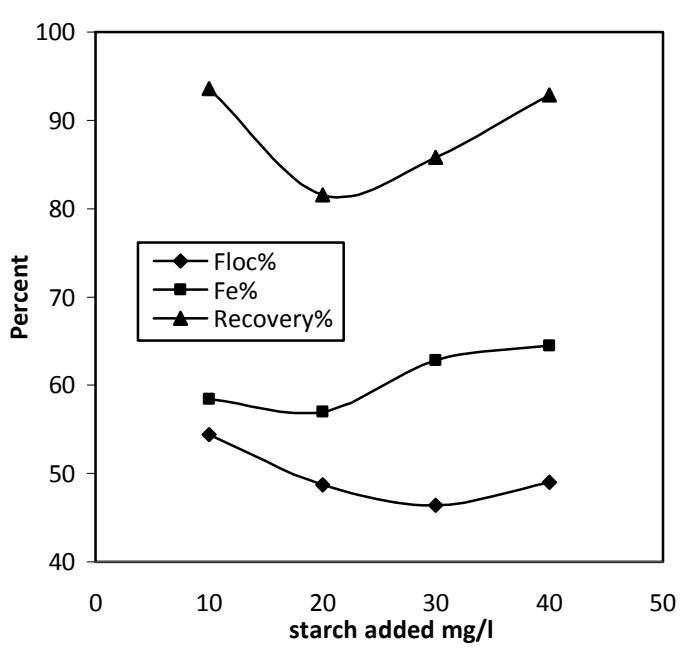

Fig. (7). Selective Flocculation of hematite-quartz mixture as a function of starch addition at $\mathrm{pH} 9.0$. 
achieve $57.2 \%$ Fe with $71 \%$ recovery from a feed containing around $38.9 \% \mathrm{Fe}$.

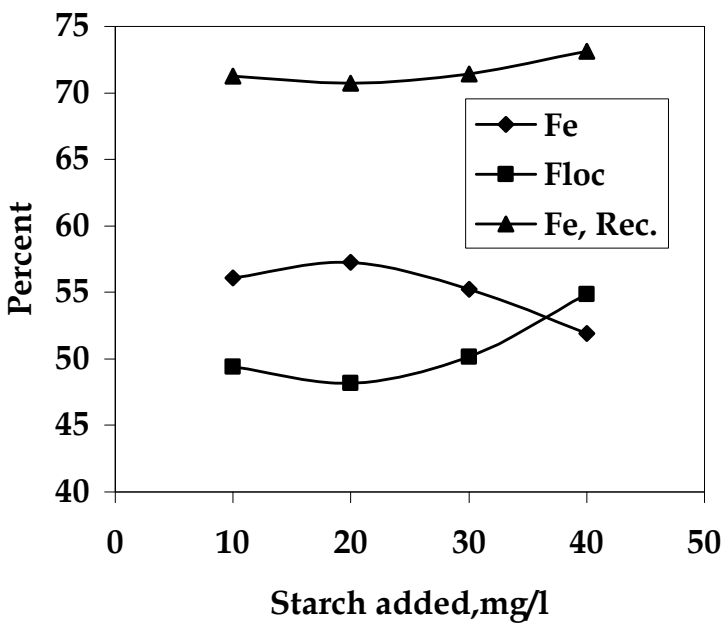

Fig. (8). Selective flocculation of BHQ ore as a function of starch addition at $\mathrm{pH} 9.0$.

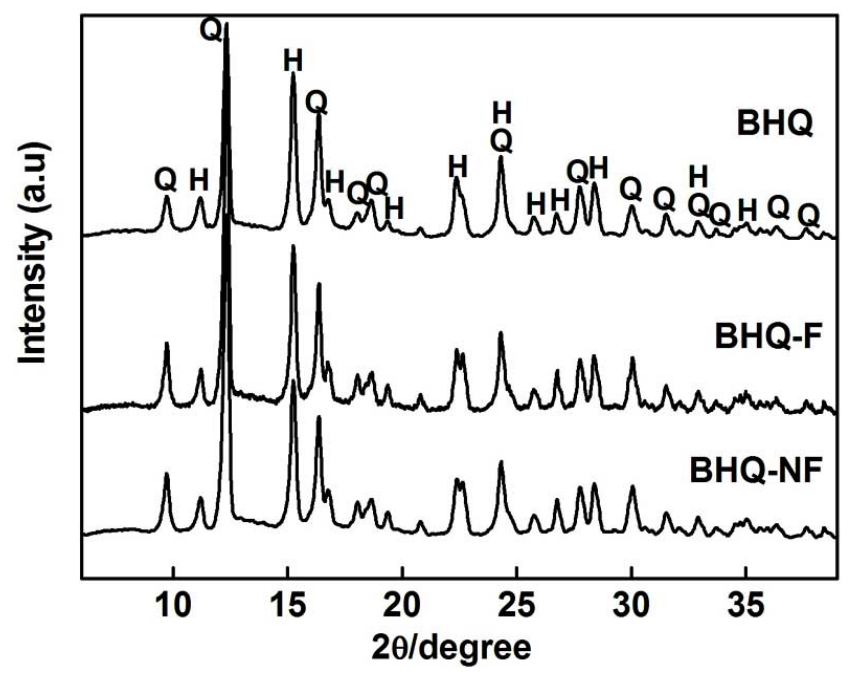

Fig. (9). XRD spectra of BHQ, flocculated (BHQ-F) and non flocculated samples (BHQ-NF).

\section{XRD Studies}

The XRD results of flocculated and non-flocculated products along with the BHQ ore sample are shown in Fig. (9). Two prominent mineral peaks of quartz and hematite are observed in all the three samples. It is also observed that the diffraction pattern of BHQ ore and the non-flocculated
(BHQ-NF) fraction are identical. The intensity of diffraction peaks of quartz in the flocculated BHQ (BHQ-F) has slightly decreased where as, the peak intensity of hematite is enhanced slightly. According to the results of chemical analysis, the flocculated mass contains about $57.2 \% \mathrm{Fe}$, and the non-flocculated sample contains about $21.9 \% \mathrm{Fe}$. The quantitative estimation of different minerals as calculated by stereomicroscopy and by liquid mount thin sections is shown in Table 2. The corresponding iron and silica values of the three products are also shown in the same table. The results indicate that hematite content in the flocculated material is $77.2 \%$ in comparison to $16.7 \%$ in the non-flocculated material. The corresponding quartz value in the flocculated material is only $4.5 \%$ where as, it is 80.6 and $33.0 \%$ in the BHQ and the non-flocculated material respectively. Thus these results point to the fact that flocculation of hematite particles from BHQ ore has taken place in the presence of quartz.

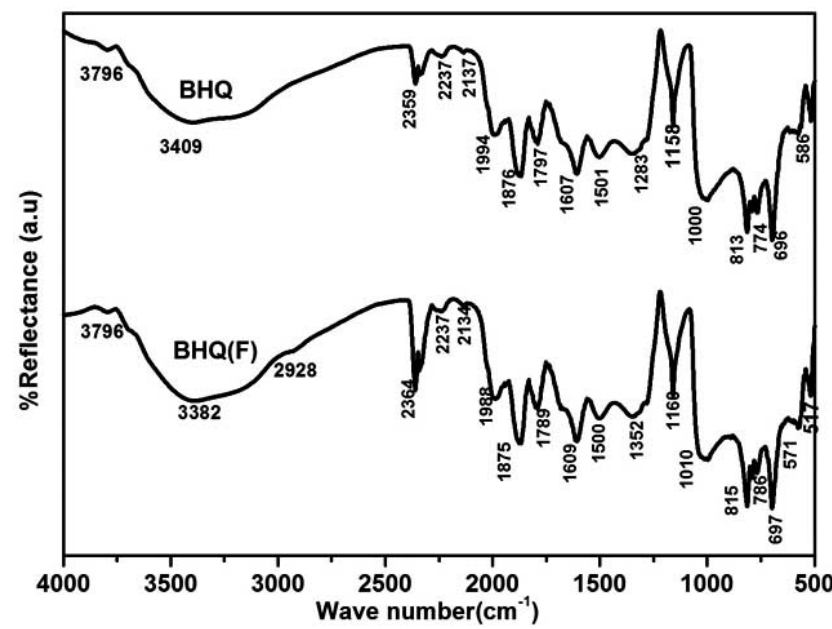

Fig. (10). FTIR spectra of BHQ and BHQ-flocculated with starch molecules.

\section{FTIR Studies}

FTIR spectra of BHQ sample and starch adsorbed BHQ sample is shown in Fig. (10) and their spectral assignments are given in Table 3. The FTIR absorption profiles of the samples showed peaks at 774, 1283 and $696 \mathrm{~cm}^{-1}$, corresponding to quartz. The hematite peaks have appeared near 1158, 774 and $517 \mathrm{~cm}^{-1}$. The peaks at $1000 \mathrm{~cm}^{-1}$ are assigned due to $(\mathrm{Si}-\mathrm{OH})$ stretching. The spectrum shows that the bands above $3400 \mathrm{~cm}^{-1}$ is due to the presence of absorbed water. The broad peak that appears at $3134 \mathrm{~cm}^{-1}$ is due to $\mathrm{OH}$ group coupling with minerals. The FTIR spectra of starch generally shows four peaks at 3300, 610, 1350 and $1000 \mathrm{~cm}^{-1}$

Table 2. Quantitative Mineralogy of BHQ ore and Products

\begin{tabular}{|c|c|c|c|c|c|}
\hline Sample & Hematite, $\%$ & Goethite, $\%$ & Quartz, $\%$ & Fe, $\%$ & SiO \\
\hline \hline BHQ-iron ore & 48.9 & 19.1 & 33.0 & 38.97 & 42.54 \\
\hline BHQ-Flocculated & 75.2 & 19.3 & 4.5 & 57.2 & 16.3 \\
\hline BHQ-Non-flocculated & 16.7 & 2.7 & 80.6 & 21.9 & 64.3 \\
\hline
\end{tabular}


corresponding to water molecules that comprise of $\mathrm{O}-\mathrm{H}$ group vibration, bending mode angles of O-C-H, C-C-H, and $\mathrm{C}-\mathrm{O}-\mathrm{H}$. Absorption peaks due to water molecules are small in starch spectra. There are also some strong absorption peaks in the region between 1200 and $900 \mathrm{~cm}^{-1}$. The starch peaks have shifted and appears at 3382, 571, 1352 and 1010 $\mathrm{cm}^{-1}$ indicating that starch molecules are adsorbed on BHQ surfaces [23-27].

Table 3. FTIR Spectral Band Position and their Assignment for BHQ and Starch Adsorbed Sample

\begin{tabular}{|l|l|}
\hline Band Position, $\mathbf{c m}^{-1}$ & Assignments \\
\hline \hline 3134 & -OH stretching band \\
\hline 3796,3400 & Si-OH stretching mode, absorbed water \\
\hline 1607 & Fe-O, Hematite \\
\hline $1158,734,517$ & Hematite \\
\hline 1000 & $($ Si---OH $)$ \\
\hline $1158,774,517$ & quartz \\
\hline 1501,1283 & Asymmetric O-C-O stretching vibration \\
\hline $1000-500$ ( BHQ-Starch) & Sharp band due to starch absorption \\
\hline
\end{tabular}

\section{Scanning Electron Microscope Studies}

The electron micrographs of BHQ ore, flocculated and non-flocculated particles are shown in Fig. (11). The ore samples consisted of various size particles but mostly of below $20 \mu \mathrm{m}$ size. The flocculated particles are relatively large in comparison to the non-flocculated material. It is noticed that the iron-bearing particles are present in coarser size compared to the silica bearing particles. In contrast, the particles in the non-flocculated fraction are relatively fine.

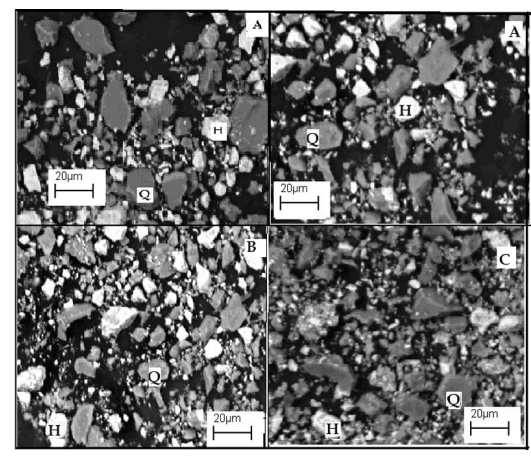

Fig. (11). SEM micrographs of BHQ, flocculated and non-flocculated particles. $\quad(\mathrm{A}=\mathrm{BHQ}(\mathrm{Feed}), \mathrm{B}=\mathrm{BHQ}(\mathrm{F}), \mathrm{C}=\mathrm{BHQ}(\mathrm{NF}), \mathrm{H}=$ Hematite, $\mathrm{Q}=\mathrm{Quartz}$ ).

\section{Flocculation Mechanism}

In a selective flocculation process, it is necessary to have particles of stable dispersion for which enough kinetic energy must be provided to the suspension to overcome the potential energy barrier. The energy barrier can be eliminated by neutralization of surface charge via adsorption of a suitable flocculant onto the particle surface which in turn act to bridge between the particles. Therefore, in the flocculation process high molecular weight flocculant is added to favor the bridging. In hematite flocculation system, it has been proved by several adsorption experiments that amylopectin has a greater affinity for hematite compared to amylose. The superior flocculation and adsorption ability of amylopectin has been attributed to its larger molecular weight and branched structure. Hanumantha Rao [28] et al., have found that potato starch is a better selective flocculant containing amylopectin in the selective flocculation of iron ore slimes. The natural polymers are non-toxic, readily available in natural resources and are biodegradable compared to synthetic flocculants.

In the flocculation process of BHQ ore containing hematite and quartz, it has been observed that large and dense flocs of hematite are formed with the addition of potato starch in alkaline conditions while under the same conditions the fine quartz particles remain dispersed. These results are also in agreement with the results of individual minerals mixtures and BHQ ore tests as shown in Figs. (3-8). In fact, available literature on iron oxide and quartz separation using starch and polyacrylic acid indicates that natural starch is a better flocculant than the synthetic one [29].

The photographs of flocculated and non-flocculated particles are shown in Fig. (12). It is seen that most of the iron particles are blackish grey in color where as the nonflocculated material which is mostly a mixture of quartz and fine hematite are reddish in colour.

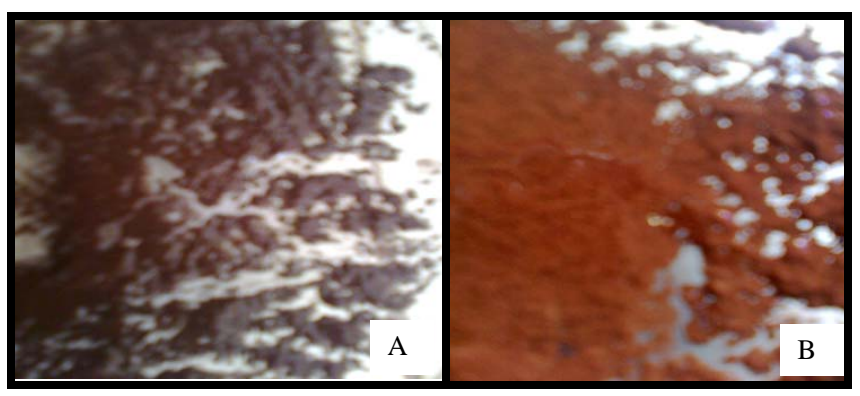

Fig. (12). Flocculated and non-flocculated particles. ( $A=$ Flocculated iron particles $\mathrm{B}=$ Non-flocculated quartz particles).

\section{CONCLUSIONS}

The banded hematite quartzite iron ore is a low grade iron ore and contains only $39 \% \mathrm{Fe}$, with $42.5 \% \mathrm{SiO}_{2}$, and $1.0 \% \mathrm{Al}_{2} \mathrm{O}_{3}$. The mineralogical characterization studies indicate the presence of hematite and quartz as the major minerals. The initial flocculation experiments with synthetic mixture of hematite and quartz indicates a hematite concentrate of $64.5 \% \mathrm{Fe}$ with $92.0 \%$ recoveryis achievable from a feed containing $34 \%$ Fe. Selective flocculation results with custicised starch as the flocculant to recover iron values from the sample indicates that it is possible to separate the iron values from other impurities at $\mathrm{pH}$ 9.0. The change of absorption peaks of starch through FTIR provides evidence the adsorption of starch on hematite particle present in BHQ. These particles agglomerate as viewed under SEM. The results of selective flocculation studies at particles size of below $20 \mu \mathrm{m}$ indicates that a concentrate of $57.2 \% \mathrm{Fe}$ with $71 \%$ recovery could be achieved. The concentrate can 
be blended with some high grade iron concentrate to use in iron and steel making.

\section{ACKNOWLEDGEMENT}

Financial assistance from CSIR in the form of network project to the authors is gratefully acknowledged.

\section{REFERENCES}

[1] B. Das, B.K. Mishra, S. Prakash, S.K. Das, P.S.R. Reddy, and S.I. Angadi, "Magnetic and flotation studies of banded hematite quartzite (BHQ) ore for the production of pellet grade concentrate", Int. J. Miner. Metall. Mat., vol. 17, 6, pp. 675-682, December 2010

[2] W. Yu-hua, H. Chuan-bing, H. Yue-hua, H. Ye-min and L. Ye, "Beneficiation of diasporic-bauxite ore by selective flocculation with a polyacrylate flocculant “, Miner. Eng.,vol. 21, pp. 664-672, March 2008

[3] H. Wang, "Improvement in Flotation and Filterability of Fine Coal Slime by Selective Flocculation”, J. Miner. Sci. vol.39, 4, pp. 410414, July 2003.

[4] J. Rubio and A.M. Marabini, "Factors affecting the selective flocculation of hydroxyapatite from quartz and/or calcite mixtures", Int. J. Miner. Process, vol. 20, 1-2, pp. 59-71, June 1987.

[5] Y.A. Attia "Fine Particle Separation by Selective Flocculation", Sep. Sci. Tech., vol. 17, 3, pp. 485-493, 1982.

[6] B. Beklioglu and A. Arol, "Selective flocculation behavior of chromite and serpentine", Phy-Chem. Problems of Miner. Process., vol. 38, pp. 103- 112, June 2004.

[7] Pradip, "Processing of alumina rich Indian iron ore slimes", Int. J. Miner., Metals Mat. Eng, vol. 59 (5), pp. 551-568, 2006.

[8] Pradip, S.A. Ravishankar, T.A.P. Sankar and N.K. Khosla, "Beneficiation studies on alumina-rich Indian iron ores slimes using selective dispersants, flocculants and flotation collectors", Proceedings, XVIII Int. Miner. Proc. Cong., Sydney, Australia, AusIMM, 1993, pp. 1289-94.

[9] P.K. Weissenborn, L.J. Warren and J.G. Dunn, "Optimization of selective flocculation of ultrafine iron ore", Int. J. Miner. Process., vol. 42, pp 191-213, December 1994

[10] D.F. Bagster and J.D. Mcilveny, "Studies in the selective flocculation of hematite from gangue using high molecular weight polymer, Part 1: Chemical Factors”, Int. J. Miner. Process., vol. 14, pp. 1-20, January 1985.

[11] S.A.R. Shankar, Pradip, M.G. Deo, R.A. Kulkarni, and S. Gundiah, "Selective flocculation of iron oxide-kaolin mixtures using a modified polyacrylamide flocculant", Bulletin of Mat. Sci., vol. 10, pp. 423-433, August 1988.

[12] G.C. Sresty, and P. Somasundaran, "Selective flocculation of synthetic mineral mixture using modified polymers", Int. J. Miner. Process, vol. 6, pp. 303, September 1980

[13] S.A. Ravishankar, Pradip, N.K. Khosla, "Selective flocculation of iron oxide from its synthetic mixtures with clays: a comparison of polyacrylic acid and starch polymers", Int. J. Miner.Process, vol. 43, pp. 235-247, June 1995.

[14] F.F.O. Orumwense and J.C. Nwachukwu, "Flocculation studies on hematite-silica system using polymeric flocculants", Indian $J$ Chem. Techno., vol. 7, pp. 23-29, 2000.

[15] K.H. Rao, and K.S. Narasimhan,"Selective flocuulation applied to Barsuan iron ore tailings", Int. J. Miner. Process. vol. 14, pp. 67-75, January 1985.

[16] P.K. Weisborn, L.J. Warren, J.G. Dunn, "Optimization of selective flocculation of ultrafine iron ore", Int. J. Miner. Process., vol. 42(3-4), pp. 191- 231, December 1994.

[17] P.K. Weisborn, L.J. Warren, J.G. Dunn, "Selective flocculation of ultrafine iron ore 2.Mechanism of selective flocculation", Colloids Surf. A: Physico. Chem. Eng. Asp., vol. 99 (1), pp. 29-43, June 1995.

[18] I. Dogu and A. I. Arol "Separation of dark-colored minerals from feldspar by selective flocculation using starch", Powder Technol., vol. 139, 3, pp. 258-263, January 2004.

[19] Liuyin Xia, Hong Zhong, Guangyi Liu and Shuai Wang, "Utilization of soluble starch as a depressant for the reverse flotation of diaspore from kaolinite", Miner. Eng.,vol. 22, 6, pp.560-565, May 2009.

[20] C. K. Simi and T. Emilia Abraham, "Hydrophobic grafted and cross- linked starch nanoparticles for drug delivery", Bioprocess and Biosyst. Eng., vol. 30, (3), pp. 173-180, May 2007.

[21] K. Sujith Varma, "Sago starch use in biomedical applications", PHARMABIZ.com, October 06, 2010.

[22] R.F.T. Stepto, "Theromplastic starch and drug delivery capsules", Polym. Int., vol. 43, pp. 155-158, June 1979.

[23] K. Lizuka and T. Aishima "Starch gelation process observed by FTIR/ATR spectrometry with multivariate data analysis", $J$. of Food Sci. vo. 64, pp. 653-658, July 1999.

[24] J.L. Rendon, and C.J. Serna, "IR spectra of powder hematite; effect of particle size and shape", Clay Miner., vol. 16, pp.375-381, August 1981

[25] N.S. Samsava, L.G. Ilchenko, M.M. GolD'man, and L.P. Ni, "IR spectroscopic study of the adsorption of polyacrylamide on hematite”, J. Appl. Spectrosc., vol.23, pp. 963-966, July 1975.

[26] Paul F. McMillan and Richard L. Remmele Jr, "Hydroxylsites in $\mathrm{SiO}_{2}$ glass a note on Infrared and Raman spectra", Am. Mineralogist., vol. 71, pp. 772-778, January 1986.

[27] J. Muto, H. Nagahama, and T. Hasmimoto, "Microinfrared reflection spectroscopic application to the detection of hydrogen related species of natural quartz", J. Microsc., vol. 216, pp. 222-228, December 2004

[28] K. Hanumantha Rao, A. Nayak, S.N. Mohapatra, and K.S Narasimhan, "Selective flocuulation for the recovery of iron ore from Kudremukh tailings", Min.Eng., vol. 37,pp. 1312-1315, 1985.

[29] P. Somasundaran, K. K. Das and X. Yu., "Selective Flocculation", Curr. Opin. Colloid Interface Sci. vol. 1 (4), pp. 530-534, 1996.

This is an open access article licensed under the terms of the Creative Commons Attribution Non-Commercial License (http://creativecommons.org/licenses/ by-nc/3.0/) which permits unrestricted, non-commercial use, distribution and reproduction in any medium, provided the work is properly cited. 